\title{
DIREKTNA PARCIJALNA PITANJA IZVEDENA POMOĆU PROSTIH UPITNIH ZAMENICA U FRANCUSKOM JEZIKU I NJIHOVI EKVIVALENTI U SRPSKOM ${ }^{*}$
}

U francuskom jeziku, direktna parcijalna pitanja izvedena pomoću prostih upitnih zamenica podrazumevaju složen sistem u okviru koga su mnogi elementi podložni varijaciji. Pre svega, odabir prostih upitnih zamenica u konkretnom upitnom iskazu zavisi od toga da li se odnosi na bića (qui) ili na stvari i pojmove (que/qu', quoi). Kada se odnose na stvari i pojmove, proste upitne zamenice, koje spadaju u nepromenljivu vrstu reči, imaju svoj nenaglašen (que/qu') i naglašen oblik (quoi), a njihova upotreba zavisi od pozicije proste upitne zamenice u upitnom iskazu, kao i od toga da li je ona upotrebljena samostalno ili ne, uz predlog ili bez njega. Između ostalog, u zavisnosti od funkcije upitne zamenice u rečenici, često postoje dvojni upitni oblici: neprošireni (koji zahtevaju upotrebu inverzije osim ako upitna reč ima funkciju subjekta) i prošireni pomoću upitnog izraza est-ce que, est-ce qui (koji zahtevaju isti red reči kao u izjavnoj rečenici). Najzad, u govornom jeziku, upotreba direktnih parcijalnih pitanja izvedenih pomoću prostih upitnih zamenica pokazuje strukturnu varijabilnost koja nosi različita stilska obeležja. U našem radu, oslanjajući se na relevantnu normativnu i deskriptivnu literaturu, kao i na analizu korpusa, nastojaćemo da utvrdimo koji su oblici, u srpskom jeziku, ekvivalentni navedenim direktnim parcijalnim pitanjima.

Ključne reči: parcijalna pitanja, upitne zamenice, francuski jezik, srpski jezik.

\section{UVOD}

Opšta podela pitanja, zasnovana na njihovim strukturnim karakteristikama, ali i na vrsti očekivanog odgovora koji treba da usledi, podrazumeva najčešće sledeća dva osnovna tipa: totalno pitanje (fr. interrogation totale) i parcijalno pitanje (fr. interrogation partielle). Totalnim pitanjem se označava pitanje koje se odnosi na celu rečenicu, te se njime obično traži informacija o tome da li se data situacija (radnja, zbivanje, proces, stanje i slično) u celini realizuje ili ne, te je

1 radusin.bardic@gmail.com

Ovaj rad je nastao u okviru projekta br. 178002 pod nazivom Jezici i kulture u vremenu i prostoru, koji finansira Ministarstvo prosvete, nauke i tehnološkog razvoja Republike Srbije. 
osnovni tip odgovora potvrdan ili odričan, a parcijalnim pitanjem označava se pitanje pomoću koga se traži informacija o sadržini nekog dela upitne rečenice markiranog upitnom rečju (na primer, o vršiocu radnje, predmetu radnje, okolnostima vršenja glagolske radnje, osobini nekog pojma, i slično), te je očekivani odgovor izraz kojim se iskazuje ta sadržina i upotpunjuje smisao cele rečenice. Prema tome, parcijalna pitanja nužno sadrže upitne reči među koje se, $\mathrm{u}$ francuskom jeziku, ubrajaju: upitni determinativi (fr. déterminants/adjectifs interrogatifs) quel, quelle, quels, quelles, upitne zamenice (fr. pronoms interrogatifs), koje mogu biti proste (fr. pronoms interrogatifs simples): qui, que, quoi i složene (fr. pronoms interrogatifs composés): lequel, laquelle, lesquels, lesquelles, kao i upitni prilozi (fr. adverbes interrogatifs) u koje spadaju oblici za mesto: où, vreme: quand, način: comment, količinu: combien, uzrok: pourquoi. U srpskom jeziku, među upitne reči ubrajaju se upitno-odnosne zamenice koje mogu biti imeničke: $k o(t k o)$, šta(što) i pridevske koje služe za postavljanje pitanja o identitetu: koji, koja, koje, pripadanju i poreklu: čiji, čija, čije, osobinama: kakav, kakva, kakvo, veličini ili količini: koliki, kolika, koliko, kao i upitni prilozi za mesto: gde (gdje), kud(a), kamo, otkud(a), odakle, dokle, vreme: kad(a), od kada / otkad(a), do kada / dokad(a), dokle, način: kako, količinu: koliko i uzrok: zašto.

Tema našeg rada biće ograničena na direktna parcijalna pitanja izvedena pomoću prostih upitnih zamenica u francuskom jeziku i na njihove ekvivalente u srpskom jeziku.

U prvom delu rada, nastojaćemo da sagledamo osnovne karakteristike prostih upitnih zamenica u francuskom jeziku oslanjajući se na odabranu normativnu i deskriptivnu literaturu koja se bavi ovom tematikom. Posebno će nas zanimati oblici i funkcija prostih upitnih zamenica u direktnim parcijalnim pitanjima, njihov položaj u upitnim iskazima i uticaj na raspored osnovnih rečeničnih konstituenata, kao i stilska vrednost koja se pridaje pojedinim varijetetima. Nakon toga, na sličan način nastojaćemo da predstavimo opšte karakteristike imeničkih upitnih zamenica u srpskom jeziku budući da se ovi oblici smatraju ekvivalentnim oblicima prostih upitno-odnosnih zamenica u francuskom jeziku u gramatikama francuskog jezika namenjenim srbofonim govornicima (Drašković, 1992: 129-130, Papić, 1992: 150-154, Jovanović i dr., 1991: 515-517). Ovaj deo rada ilustrovaćemo primerima iz našeg korpusa koji čine dramska književna dela na francuskom i srpskom jeziku, kao i odabranom rečničkom građom čiji je spisak dat na kraju rada. Upitne oblike direktnih parcijalnih pitanja izvedenih pomoću prostih upitnih zamenica koji su specifični za francuski razgovorni jezik ilustrovaćemo primerima iz igranih filmova koji su, takođe, navedeni na kraju rada, uz spisak korištene literature.

$\mathrm{U}$ drugom delu rada, hipotezu o imeničkim upitno-odnosnim zamenicama $\mathrm{u}$ srpskom jeziku kao ekvivalentnim oblicima prostih upitnih zamenica u direktnim parcijalnim pitanjima u francuskom jeziku nastojaćemo da proverimo kontrastivnom jezičkom analizom. Ona će biti zasnovana na analizi dela korpusa sastavljenog od odabranih dramskih književnih dela na francuskom i njihovih 
objavljenih prevoda na srpskom jeziku, kao i od odabranih dramskih književnih dela na srpskom i njihovih objavljenih prevoda na francuskom jeziku.

\section{PROSTE UPITNE ZAMENICE U FRANCUSKOM JEZIKU}

\subsection{Oblici prostih upitnih zamenica}

Proste upitne zamenice imaju sledeće osnovne oblike: qui, que (qu') i quoi, te možemo reći da one imaju delimično iste oblike kao i relativne zamenice (izuzev relativne zamenice dont, koja nema odgovarajuću upitnu zamenicu, i relativne zamenice où sa mesnim i vremenskim značenjem, koja u klasifikaciji upitnih reči odgovara samo upitnom prilogu za mesto: où $)^{2}$.

Njihova upotreba zavisi od toga da li se odnose na lica ili na stvari i pojmove, kao i od toga koju funkciju vrše u rečenici.

Upitna zamenica qui odnosi se na lica ${ }^{3}$ i podrazumeva se da je muškog roda u jednini, sem ako kontekst ne upućuje na to da se ova zamenica odnosi na muški rod u množini ili na ženski rod u jednini ili množini ${ }^{4}$.

Upitna zamenica qui može da bude upotrebljena bez predloga (1) ili da joj prethodi predlog (2):

(1) Qui te dit que je ne suis pas heureux? (ACCa: 147),

(2) Vers qui donc, dans le monde, aurais-je pu me tourner, sinon vers celle qui avait tué en même temps que moi ? (ACMa: 245).

Upitne zamenice que (qu') i quoi odnose se na stvari i pojmove. Upitna zamenica que ispred suglasnika ima pun oblik (3) dok ispred samoglasnika i nemog h ima elidovani oblik $q u$ ' (4):

(3) Que bois-tu, Mereia? (ACC : 70),

(4) Qu'a-t-il dit? (ACCa: 142).

Ako upitnoj zamenici prethodi predlog, ne upotrebljava se que, već jedino naglašeni oblik quoi:

(5) À quoi penses-tu? (ACCa: 142),

(6) De quoi s'agit-il? (ACCa: 122),

(7) Sur quoi aurais-tu pleuré? (MDHa: 26).

Naglašeni oblik quoi upotrebljava se, takođe, ako upitnoj zamenici prethodi glagol:

(8) Vous faites quoi, M. Dufayel ? (FDAP),

2 U relativne zamenice spadaju i oblici lequel, laquelle, lesquels, lesquelles koji morfološki u potpunosti odgovaraju složenim upitnim zamenicama.

3 Upotreba upitnih zamenica nije jasno razgraničena kada su u pitanju životinje. U principu, upitna zamenica que odnosi se i na životinje, ali ponekad je moguće upotrebiti i qui za životinje, na primer, za psa kao kućnog ljubimca koji ima svoje ime (Casimir, Milou...) (Riegel, Pellat, Rioul, 2004: 394).

4 Moris Grevis (Maurice Grevisse) u svojoj gramatici navodi primere u kojima se upitna zamenica qui odnosi na imenicu ženskog roda u jednini: Quelles idiotes! - Qui est idiote? Ma sœur, ma mère, ma nièce ? (Jean Giraudoux, L'Apollon de Bellac, 1942), na imenicu muškog roda u množini: Qui étaient ces garçons ? (Vercors, Les Armes de la nuit, 1951) i na imenicu ženskog roda u množini: Qui étaient ces dames et d'où venaient-elles? (Henri Bosco, Les Balesta, 1956), (Grevisse, 1969: 500). 
ako joj sledi predlog de i pridev:

(9) Quoi de neuf? (LPR),

kao i ako je upotrebljena samostalno:

(10) Regardez mes lauriers. - Ben quoi ? (FDAP).

\subsection{Funkcije prostih upitnih zamenica $i$ red reči u direktnim parcijalnim pitanjima}

Prosta upitna zamenica qui može biti upotrebljena u funkciji subjekta za lica u svom osnovnom obliku $(1,11)$, pri čemu se obavezno čuva kanonski red reči (subjekat + glagol + objekat)

(11) Si je dors, qui me donnera la lune? (ACCa: 27).

$\mathrm{U}$ istoj funkciji, prosta upitna zamenica qui može se naći i u svom alternativnom, proširenom obliku qui est-ce qui kada se, takođe, čuva kanonski red reči:

(12) Qui est-ce qui a un mouchoir? (ELM).

Prosta upitna zamenica qui može biti upotrebljena i u funkciji imenskog dela predikata kada zahteva upotrebu proste inverzije, kako u slučaju kada je u funkciji subjekta upotrebljena nenaglašena lična zamenica (13), tako i u slučaju kada je u funkciji subjekta upotrebljena imenska sintagma (14):

(13) Qui es-tu? (MDHa: 35),

(14) Qui est votre mari ? (ACMa: 238).

Iako normativna gramatika propisuje upotrebu proste inverzije u slučaju kada upitna zamenica qui vrši funkciju imenskog dela predikata, u savremenom francuskom razgovornom jeziku postoji težnja ka uspostavljanju kanonskog reda reči, i to tako da je upitna zamenica qui upotrebljena u finalnoj (15) ili, čak, inicijalnoj poziciji (16):

(15) Vous êtes qui ? (FDAP),

(16) Qui c'est? (MDHa: 120).

Prema pravilima normativne gramatike, upitna zamenica qui u funkciji direktnog objekta zahteva, takođe, inverziju:

(17) Mais toi, qui sers-tu? (ACCa: 126).

Međutim, i u tom slučaju, postoji tendencija ka očuvanju kanonskog reda reči, i to tako da je upitna zamenica qui upotrebljena u finalnoj poziciji:

(18) Il guette... qui, maintenant? (Jean Giono, Colline, 1929) (TLFI).

Prosta upitna zamenica qui, pored svog alternativnog proširenog oblika koji se koristi u funkciji subjekta: qui est-ce qui, ima i svoj alternativni prošireni oblik koji se koristi u funkciji objekta: qui est-ce que koji podrazumeva upotrebu kanonskog reda reči. Ponekad se upravo zahvaljujući proširenim upitnim oblicima izbegava dvosmislenost koja bi mogla nastati ukoliko bi upitna zamenica qui bila

\footnotetext{
Kada se govori o kanonskom redu reči u francuskom jeziku, podrazumeva se da objekat nije upotrebljen u vidu zamenice.
} 
upotrebljena sama u inicijalnoj poziciji u rečenici, te kada ne bi bilo jasno da li ona vrši funkciju subjekta ili direktnog objekta ${ }^{6}$.

Ako je upitna zamenica qui upotrebljena u svom neproširenom obliku uz predlog, nužno je, u skladu sa pravilima standardnog francuskog jezika, da bude upotrebljena inverzija (2).

Prosta upitna zamenica que (qu') može biti upotrebljena u funkciji subjekta za stvari i pojmove isključivo u svom proširenom obliku?:

(19) Qu'est-ce qui te prend? (ACCa: 34).

Prema tome, u navedenoj funkciji, za razliku od proste upitne zamenice za lica (qui / qui est-ce qui), prosta upitna zamenica za stvari i pojmove glasi: qu'est-ce qui i nema alternativni oblik. Postoji ipak jedan slučaj kada upitna zamenica que (qu') može imati funkciju subjekta, a to je kada je upotrebljena uz unipersonalne glagole, te vrši funkciju ,pravog subjekta“ (fr. le sujet réel), prilikom čega je obavezna inverzija glagola $\mathrm{i}$,prividnog subjekta“ (fr. le sujet apparent) ${ }^{8}$ :

\section{(20) Que faut-il faire? (ACCa: 73),}

(21) Mais alors, qu'est-il donc arrivé ? (ACMa: 240).

Navešćemo i specifičan primer upotrebe upitne zamenice que (qu') u funkciji „pravog subjekta“ gde ,prividni subjekat“ u obliku neutruma $i l$ nije iskazan, mada on obično stoji uz unipersonalne glagole:

(22) Qu'importe? (ACCa: 39).

Prosta upitna zamenica que (qu') može vršiti funkciju imenskog dela predikata u svom osnovnom obliku kada je obavezna inverzija, kako u slučaju kada je u funkciji subjekta upotrebljena nenaglašena lična zamenica (23), tako i u slučaju kada je u funkciji subjekta upotrebljena imenska sintagma (24):

(23) Que deviendrais-je loin de vous? (ACMa: 196),

(24) Que deviendrait le monde si les condamnés se mettaient à confier au bourreau leurs peines de cour? (ACMa: 195).

$\mathrm{U}$ istoj funkciji, prosta upitna zamenica que (qu') može se naći i u svom alternativnom, proširenom obliku qu'est-ce que kada se čuva kanonski red reči:

(25) Qu'est-ce que c'est le film dans lequel tu joues? (MDHa: 53).

Iako normativna gramatika propisuje upotrebu proste inverzije u slučaju kada upitna zamenica que (qu') u svom neproširenom obliku vrši funkciju imenskog dela predikata, u savremenom francuskom razgovornom jeziku postoji težnja ka

Žan-Klod Ševalije (Jean-Claude Chevalier) navodi sledeći primer: Qui voit Pierre? napominjući da on može biti dvosmislen, te da znači: Qui est-ce que voit Pierre?, ali i: Qui est-ce qui voit Pierre? (Chevalier, 1964: 93).

7 Pjer Le Gofik (Pierre Le Goffic) beleži iznimni slučaj kada se upitna zamenica quoi (kojoj sledi predlog de + dopuna) može naći u funkciji subjekta: Quoi d'autre aurait pu lui être aussi agréable ? (Le Goffic, 1993: 103).

8 Međutim, moguće je, uz unipersonalne glagole, iskazati pitanje i u proširenom obliku, te tada dolazi do dvostruke mogućnosti ortografisanja: Qu'est-ce qu'il se passe? i Qu'est-ce qui se passe? (Papić, 1992: 153). 
uspostavljanju kanonskog reda reči, i to na taj način da se koristi upitna zamenica quoi u finalnoj poziciji:

(26) C'est quoi ? - C'est quoi «quoi»? (ELM),

(27) Hé, c'est quoi ce tatouage, Souleymane? (ELM).

Upitna zamenica que (qu') u funkciji direktnog objekta obavezno zahteva inverziju $(3,4,28)$ :

(28) Que fait-elle, que pense-t-elle dans sa chambre d'hôtel, le cœur fermé, les yeux secs, toute nouée au creux d'une chaise? (ACMa: 201).

Međutim, ukoliko je u ovoj funkciji upotrebljena upitna zamenica u svom proširenom obliku: qu'est-ce que, očuvan je kanonski red reči ${ }^{9}$ :

(29) Qu'est-ce que vous voulez? (ACCa: 31 ).

I u ovom slučaju, postoji tendencija ka očuvanju kanonskog reda reči u francuskom razgovornom jeziku, i to tako da je upitna zamenica quoi upotrebljena $\mathrm{u}$ finalnoj poziciji $(8,30)$ :

(30) Tu cries quoi ? (MDHa: 90).

Kao što je to ranije već rečeno, uz predloge ne može da stoji upitna zamenica que (qu'), već jedino njen naglašeni oblik quoi, i tada pravila standardnog francuskog jezika nalažu obaveznu upotrebu inverzije $(5,6,7)$. Međutim, i u ovom slučaju dolazi do odstupanja od normativnih načela u razgovornom jeziku, te je očuvan kanonski red reči na taj način što se predlog + quoi koristi u finalnoj poziciji:

(31) Et tu seras avancée à quoi si *j'suis puni? (ELM),

kao i u inicijalnoj poziciji:

(32) À quoi tu rêvais? (MDHa: 44).

U Tabeli 1, po uzoru na Grammaire méthodique du français (Riegel et al., 2004: 207) ${ }^{10}$, dajemo prikaz prostih upitnih zamenica u francuskom jeziku gde su ukrštena tri kriterijuma: referent (lice/stvari i pojmovi), funkcija (subjekat, imenski deo predikata, direktni objekat, predlog + prosta upitna zamenica), proširivanje oblika $(\mathrm{N}=$ neprošireni, $\mathrm{P}=$ prošireni):

$9 \quad$ Ako iza proširenog oblika proste upitne zamenice za stvari qu'est-ce que stoji subjekat koji nije iskazan u vidu lične nenaglašene zamenice kao ni zamenica ce ili on, moguće je upotrebiti prostu inverziju: Mais qu'est-ce que prouve cette chanson? (Alfred de Musset, Barberine, 1913, III, 2) (Grevisse, 1969: 138).

10 Za razliku od načina prikaza tabele u navedenom izvoru, u našoj varijanti izostavljeni su oblici prostih upitnih zamenica za lica koji se tamo vezuju za funkciju imenskog dela predikata, a to su: que, kao i prošireni oblik qu'est-ce que budući da se oni obično vezuju samo za oblike prostih upitnih zamenica za stvari i pojmove. U zagradu su stavljeni oni oblici koji nisu zabeleženi u našem korpusu. Kada je reč o upitnom obliku: predlog + qui est-ce que, odnosno predlog + quoi est-ce que, navešćemo primere iz gramatike francuskog jezika namenjene strancima: À qui est-ce que vous écrivez ?, De quoi est-ce que vous parlez? (Delatour, Jennepin, Léon-Dufour, Teyssier, 2004: 182-183). Napomenimo i da je u našem prikazu učinjena još jedna izmena u odnosu na originalnu tabelu: oblici predlog $+q u i$ i predlog $+q u o i$ podvedeni su pod neproširene oblike, a oblici predlog + qui est-ce que i predlog + quoi est-ce que podvedeni su pod proširene oblike, za razliku od originalne tabele gde su svi ovi oblici obeleženi kao prošireni. 


\begin{tabular}{|c|c|c|c|}
\hline \multirow[t]{2}{*}{ FUNKCIJA } & \multicolumn{2}{|c|}{ REFERENT } & \multirow[t]{2}{*}{ OBLIK } \\
\hline & LICA & STVARI I POJMOVI & \\
\hline \multirow[t]{2}{*}{ subjekat } & $q u i$ & -------- & $\mathrm{N}$ \\
\hline & qui est-ce qui & qu'est-ce qui & $\mathrm{P}$ \\
\hline \multirow{2}{*}{$\begin{array}{l}\text { imenski deo } \\
\text { predikata }\end{array}$} & $q u i$ & que & $\mathrm{N}$ \\
\hline & (qui est-ce que) & qu'est-ce que & $\mathrm{P}$ \\
\hline \multirow[t]{2}{*}{ direktni objekat } & $q u i$ & que / quoi & $\mathrm{N}$ \\
\hline & qui est-ce que & qu'est-ce que & $\mathrm{P}$ \\
\hline \multirow{2}{*}{$\begin{array}{l}\text { predlog }+ \text { prosta } \\
\text { upitna zamenica }\end{array}$} & predlog $+q u i$ & predlog $+q u o i$ & $\mathrm{~N}$ \\
\hline & (predlog + qui est-ce que) & (predlog + quoi est-ce que) & $P$ \\
\hline
\end{tabular}

\subsection{Jezička varijacija i stilske vrednosti direktnih parcijalnih pitanja izvedenih pomoću prostih upitnih zamenica}

U prethodnom poglavlju imali smo prilike da vidimo da, u pojedinim slučajevima, u zavisnosti od funkcije koju proste upitne zamenice vrše u rečenici, postoji više konkurentnih oblika direktnih parcijalnih pitanja koji imaju različitu stilsku vrednost. Iako se stilska vrednost upitnih varijeteta različito definiše u deskriptivnoj literaturi (kvantitativna i kvalitativna neusaglašenost jezičkih nivoa), zajednička je karakteristika ta da se upitni oblici izvedeni pomoću inverzije obično vezuju za negovani jezik (fr. langue soutenue), dok se upitni oblici u kojima je očuvan kanonski red reči, uprkos normativnim načelima koji propisuju upotrebu inverzije, vezuju za familijarni jezik (fr. langue familière). U Tabelama 2a i 2b, prikazaćemo kako se stilski određuje upotreba različitih oblika direktnih parcijalnih pitanja izvedenih pomoću prostih upitnih zamenica u gramatici francuskog jezika namenjenoj strancima gde se obično razlikuju tri jezička nivoa: negovani (fr. langue soutenue), svakodnevni (fr. langue courante) i familijarni (fr. langue familière) (Delatour et al., 2004: 182-183): 
Tabela 2a: Stilska vrednost različitih oblika direktnih parcijalnih pitanja izvedenih pomoću prostih upitnih zamenica za lica $\mathrm{u}$ francuskom jeziku

\begin{tabular}{|c|c|c|c|}
\hline \multirow[t]{2}{*}{ FUNKCIJA } & \multicolumn{3}{|c|}{ JEZIČKI NIVO } \\
\hline & NEGOVANI & SVAKODNEVNI & FAMILIJARNI \\
\hline \multirow[t]{2}{*}{ subjekat } & \multicolumn{3}{|c|}{ Qui a téléphoné? } \\
\hline & -------------------- & Qui est-ce qui a téléphoné? & -------------------- \\
\hline $\begin{array}{l}\text { imenski deo } \\
\text { predikata }\end{array}$ & $\begin{array}{l}\text { Qui est cette jeune } \\
\text { fille? }\end{array}$ & Cette jeune fille, qui est-ce? & $\begin{array}{l}\text { C'est qui, cette } \\
\text { jeune fille? }\end{array}$ \\
\hline \multirow[t]{2}{*}{ direktni objekat } & Qui avez-vous vu? & Qui est-ce que vous avez vu? & Vous avez vu qui? \\
\hline & $\begin{array}{l}\text { Qui Paul a-t-il } \\
\text { rencontré? }\end{array}$ & $\begin{array}{l}\text { Qui est-ce que Paul a rencontré } \\
\text { ? }\end{array}$ & $\begin{array}{l}\text { Paul a rencontré } \\
\text { qui? }\end{array}$ \\
\hline \multirow{2}{*}{$\begin{array}{l}\text { predlog }+ \text { prosta } \\
\text { upitna zamenica }\end{array}$} & À qui écrivez-vous? & À qui est-ce que vous écrivez? & Vous écrivez à qui? \\
\hline & $\begin{array}{l}\text { Avec qui Paul est-il } \\
\text { sorti? }\end{array}$ & $\begin{array}{l}\text { Avec qui est-ce que Paul est } \\
\text { sorti? / Avec qui est sorti Paul? }\end{array}$ & $\begin{array}{l}\text { Paul est sorti avec } \\
\text { qui? }\end{array}$ \\
\hline
\end{tabular}

Tabela 2a: Stilska vrednost različitih oblika direktnih parcijalnih pitanja izvedenih pomoću prostih upitnih zamenica za stvari i pojmove u francuskom jeziku

\begin{tabular}{|c|c|c|c|}
\hline \multirow[t]{2}{*}{ FUNKCIJA } & \multicolumn{3}{|c|}{ JEZIČKI NIVO } \\
\hline & NEGOVANI & SVAKODNEVNI & FAMILIJARNI \\
\hline subjekat & \multicolumn{3}{|c|}{$\begin{array}{c}\text { Qu'est-ce qui a causé l'accident? } \\
\text { Qu'est-ce qui se passe? }\end{array}$} \\
\hline $\begin{array}{l}\text { imenski deo } \\
\text { predikata }\end{array}$ & $\begin{array}{l}\text { Cet appareil, } \\
\text { qu'est-ce? }\end{array}$ & $\begin{array}{l}\text { Cet appareil, qu'est-ce que c'est } \\
\text { ? }\end{array}$ & $\begin{array}{l}\text { C'est quoi, cet } \\
\text { appareil? }\end{array}$ \\
\hline \multirow[t]{2}{*}{ direktni objekat } & Que veulent-ils? & Qu'est-ce qu'ils veulent? & $\begin{array}{l}\text { Ils veulent } \\
\text { quoi? }\end{array}$ \\
\hline & $\begin{array}{l}\text { Qu'a répondu } \\
\text { l'accusé? }\end{array}$ & $\begin{array}{l}\text { Qu'est-ce que l'accusé a } \\
\text { répondu? / Qu'est-ce qu'a } \\
\text { répondu l'accusé? }\end{array}$ & $\begin{array}{l}\text { L'accusé a } \\
\text { répondu quoi? }\end{array}$ \\
\hline \multirow[t]{2}{*}{$\begin{array}{l}\text { predlog }+ \text { prosta } \\
\text { upitna zamenica }\end{array}$} & $\begin{array}{l}\text { De quoi parlez- } \\
\text { vous? }\end{array}$ & De quoi est-ce que vous parlez? & $\begin{array}{l}\text { Vous parlez de } \\
\text { quoi? }\end{array}$ \\
\hline & $\begin{array}{l}\text { De quoi ces gens } \\
\text { discutent-ils? }\end{array}$ & $\begin{array}{l}\text { De quoi est-ce que ces gens } \\
\text { discutent? / De quoi discutent } \\
\text { ces gens? }\end{array}$ & $\begin{array}{l}\text { Ces gens } \\
\text { discutent de } \\
\text { quoi? }\end{array}$ \\
\hline
\end{tabular}

U Tabelama 2a i 2b, osenčenim poljima označeni su oni upitni oblici koji imaju neutralne stilske karakteristike, a reč je o prostim upitnim zamenicama upotrebljenim u funkciji subjekta gde je, u skladu sa normativnim načelima, uvek očuvan kanonski red reči. U navedenim tabelama zastupljeni su i upitni oblici koji nisu zabeleženi u našem korpusu, kao što su to primeri složene inverzije kojom se naročito odlikuje negovani jezik (Qui Paul a-t-il rencontré ?, Avec qui Paul 
est-il sorti ?, De quoi ces gens discutent-ils ?). Međutim, primećujemo i da u tabelama nisu iskazani neki oblici koje smo zabeleželi u našem korpusu, a kojima se naročito odlikuje familijarni jezik $(16,32)$. Reč je o upitnim oblicima u kojima je prosta upitna zamenica koja ne vrši funkciju subjekta upotrebljena u inicijalnoj poziciji u svom neproširenom obliku, a ne sledi joj inverzija, već kanonski red reči, te na taj način dolazi do direktnog kršenja normativnog načela.

\section{IMENIČKE UPITNO-ODNOSNE ZAMENICE U SRPSKOM JEZIKU}

\subsection{Oblici imeničkih upitno-odnosnih zamenica}

U serbokroatističkoj literaturi, izuzev upitnih priloga, upitne reči pomoću kojih se izvode parcijalna pitanja ponekad se morfološki različito definišu:

a) upitno-odnosne zamenice (imeničke: ko/tko; šta/što i pridevske: koji, koja, koje; čiji, čija, čije; kakav, kakva, kakvo; koliki, kolika, koliko) (Brabec, Hraste, Živković, 1968: 94-95; Stevanović, 1989: 9-12; Stanojčić, Popović, 2010: 99-106; Klajn, 2006: 88-92);

b) upitne zamenice (imeničke: ko/tko, šta/što i pridevske: koji, koja, koje; čiji, čija, čije) i zamenički pridevi (kakav, kakva, kakvo; koliki, kolika, koliko) (Barić i dr., 1997: 205);

c) upitne zamenice (ko/tko; šta/što) i zamenički pridevi (koji, koja, koje; kakav, kakva, kakvo; koliki, kolika, koliko; čiji, čija, čije) (Mirić, 1994).

$\mathrm{U}$ našem radu, usvojili smo podelu koja tradicionalno preovladava $\mathrm{u}$ serbokroatistici: podela na upitno-odnosne zamenice koje se dele na imeničke i pridevske. Sve upitno-odnosne zamenice, kako imeničke tako i pridevske, kao što im ime kaže, upotrebljavaju se i u upitnim i u odnosnim rečenicama. Zajedničko imeničkim i pridevskim upitnim zamenicama jeste to da se menjaju po padežima (izuzev vokativa).

U imeničke upitno-odnosne zamenice spadaju upitne reči koje imaju varijantnu polarizovanost oblika (srpski jezik: ko, šta; hrvatski jezik: tko, što). U srpskom jeziku, većinu funkcija upitno-objektnog značenja nosi oblik šta, dok se oblik što uglavnom sreće u upitno-kauzalnoj funkciji (Stevanović, 1989: 10-11; Mirić, 1994), te se u takvoj upotrebi što analizira kao prilog, sinonim za zašto (Klajn, 2006: 91).

Imeničke zamenice spadaju u samostalne reči, a dele se po vrsti na upitnoodnosne zamenice za lica $k o(t k o)$ i stvari i pojmove šta $(\check{s} t o)^{11}$. Navodimo najpre primere iz našeg korpusa za imeničku upitno-odnosnu zamenicu za lica ko u nezavisnom padežu (33) i u zavisnim padežima $(34,35,36,37,38)$ :

(33) Ko pravi ovde nered? (LJSŠa: 10),

(34) A zbog koga dolazi? (DKPa: 131),

${ }_{11}$ Dok je jasno razgraničena upotreba imeničkih upitno-odnosnih zamenica: na lica $(k o / t k o)$ i na nežive pojmove $(\check{s} t a / \check{s} t o)$, ova upotreba nije jasno razgraničena kada su u pitanju životinje, te se tako za neku životinju pita: Šta je to?, ali se, na primer, kaže: Kome si dao seno? - Konju. (a ne: \#Čemu si dao seno?) (Piper u: Piper i dr., 2005: 672). 
(35) A kome ste je predali? (DKPa: 130),

(36) Ama koga se odričem? (LJSŠa: 48),

(37) Pred kim da me je stid? (LJSS̆a: 67),

(38) O kome pričate? (LJSŠa: 71).

Podrazumeva se da je upitno-odnosna zamenica $k o$ ( $t k o$ ) muškog roda u jednini (osim ako kontekst ne upućuje na to da se ova zamenica odnosi na muški rod u množini ili na ženski rod u jednini ili množini). Prema tome, u složenim glagolskim oblicima, slaganje glagolskog prideva radnog je u muškom rodu:

(39) Ko je na tu veliku misao došao, dostojnu velikoga Dušana? (JSPRa: 178).

U nastavku, navodimo primere iz našeg korpusa za imeničku upitno-odnosnu zamenicu za stvari i pojmove šta u nezavisnom padežu (40) i u zavisnim padežima $(41,42,43,44)^{12}$ :

(40) Sta je to? (JSPRa: 168),

(41) Čega da me bude strah? (LJSŠa: 63),

(42) Šta gledaš tamo? (LJSŠa: 50),

(43) Ne znaš ti čime ja zarađujem lebac! - Čime? Čekićem? Budakom? Iglom $i$ koncem? Pekarskom lopatom? (LJSŠa: 65),

(44) O čemu vi to govorite? (LJSŠa: 67).

U složenim glagolskim oblicima, slaganje glagolskog prideva radnog je u srednjem rodu:

(45) Šta je bilo, Marta? (DKPa: 161).

U Tabeli 3, dat je pregled oblika imeničkih upitno-odnosnih zamenica u srpskom jeziku gde su ukrštena dva kriterijuma: referent (lica/stvari i pojmovi) i padež (nezavisni izuzev vokativa i zavisni):

\begin{tabular}{|c|c|c|}
\hline \multicolumn{3}{|c|}{ Tabela 3: Imeničke upitno-odnosne zamenice u srpskom jeziku } \\
\hline \multirow[t]{2}{*}{ PADEŽ } & \multicolumn{2}{|c|}{ REFERENT } \\
\hline & LICA & STVARI I POJMOVI \\
\hline NOMINATIV & ko & šta \\
\hline GENITIV & koga & $\check{c}$ ega \\
\hline DATIV & kome & сетети \\
\hline AKUZATIV & koga & $\check{s} t a$ \\
\hline INSTRUMENTAL & $\operatorname{kim}(e)$ & čim(e) \\
\hline LOKATIV & kome & с̌етu \\
\hline
\end{tabular}

12 U našem korpusu, imenička upitno-odnosna zamenica za stvari i pojmove šta javlja se u dativu samo u indirektnom parcijalnom pitanju: Pitam se čemu li služi tolika lepota! (LJSŠa: 28). 


\subsection{Red reči u direktnim parcijalnim pitanjima izvedenim pomoću imeničkih upitno-odnosnih zamenica}

U srpskom jeziku, u direktnim parcijalnim pitanjima uobičajeno je da upitna reč stoji na početku rečenice, te to pravilo važi kako za upitne priloge, tako i za upitno-odnosne zamenice. Inicijalna pozicija upitne reči ima neutralnu stilsku vrednost, te je svojstvena svim jezičkim stilovima.

U skladu sa gore iznetim pravilom, u našem korpusu, gotovo sva direktna parcijalna pitanja sadrže imeničku upitno-odnosnu zamenicu u inicijalnoj poziciji. Ukoliko je subjekat iskazan, često dolazi do inverzije, pri čemu glagol dolazi u medijalnu poziciju:

(46) Šta kaže devojka? (JSPRa: 218).

Međutim, ovo pravilo nije obavezujuće, te je moguće zadržati i raspored u kome subjekat dolazi ispred glagola, u zavisnosti od toga koji rečenični deo govornik nastoji da naglasi.

U izvesnim slučajevima, upitnoj reči može da prethodi neki tematski ili uvodni član (sem glagola), ,pri čemu se intenzifikuje njegova informativna funkcija“ (Popović 2004: 242). Kao što to primećuje Ljubomir Popović, ovakvo izdvajanje obično je praćeno kontrastiranjem izdvojenog člana:

Gavrilović: Ja držim sreću narodnu u jeziku i zakonu, u veličini $i$ napretku, a ne u kokardama i bojama. Ove, kako su danas izabrali, tako se mogu sutra promeniti, pa niko neće osetiti nikakvu štetu.

Šerbulić: Da se manemo toga: nego kažite, mi šta ćemo raditi, kad dođu soldati?

Gavrilović: Daćemo im kvartir i hranićemo ih. Šta znamo? (JSPRa: 184-185).

Ponekad se upitna reč može naći u finalnoj poziciji, i to tako da se nadovezuje na prethodni kontekst ${ }^{13}$. U tom slučaju, ,finalna pozicija odgovara poziciji koju bi u analognoj neupitnoj rečenici zauzimao rečenični fokus, a to je baš onaj rečenični član čije se sadržine tiče pitanje“, te se, prema tome, u toj upotrebi, „upitna i obaveštajna rečenica poklapaju sa gledišta rasporeda fokusa“ (Popović, 2004: 252). Ovakvim rasporedom, rečenica se segmentira na dva dela razdvojena pauzom i intonacijom: prvi deo, iskazan u vidu konstatacije, nadovezuje se na prehodni poznati kontekst i ne nosi upitno značenje, a u drugom delu je sadržana upitna reč koja se ne odnosi na celu rečenicu, nego na određeni rečenični član koji, ukoliko se ne nadomesti u vidu odgovora, može da ospori vrednost čitave ranije

Lj. Popović navodi sledeće primere: Bio je sluga. Služio je kome? Nauci? Koješta. (Jovan Popović, Reda mora da bude, 1932), ,Kakav je ovo život“, pričale su, ,pasji. Čuvaš poštenje, za koga?” (Novak Simić, Brkići iz Bara, 1947) (Popović, 2004: 252). 
iznete konstatacije. Često se na ova pitanja i ne očekuje odgovor, te ona spadaju $\mathrm{u}$ retorska pitanja.

Pored navedene upotrebe upitne reči u finalnoj poziciji, Lj. Popović navodi i mogućnost upotrebe takvog rasporeda u službi isticanja (poentiranja) sadržine odgovarajućeg člana ${ }^{14}$. Međutim, ni u tom slučaju nije reč o pitanju u pravom smislu te reči, već je pre reč o stilskom sredstvu pomoću koga se izbegava monotonost u naraciji i unosi se izvesna dramska napetost pre pružanja odgovarajućeg odgovora, koji može ili ne mora da se podrazumeva.

Najzad, možemo pomenuti i upotrebu upitnih reči u finalnoj poziciji u ehopitanjima $u$ vidu reakcije na prethodni iskaz koji nije u potpunosti primljen usled buke u komunikacijskom kanalu ili je primljen sa dozom neverice i čuđenja, pa se traži njegova potvrda. U tom slučaju, ponavlja se ili se prećutno podrazumeva deo primljene poruke, a umesto rečeničnog člana koji nije prenet ili koji se nastoji proveriti, upotrebljava se upitna reč sa upitnom intonacijom, i to na mestu koji traženi rečenični član zauzima u izjavnoj rečenici:

Gina: [...] Blagoje, čuješ ti mene?

Simka: Stoji ko oduzet!

Gina: Blagoje!

Blagoje: Kad je gledam, osećam se ko soba...

Gina: Ko šta?

Blagoje: ... ko soba u koju su uneli ljubičice! (LJSŠa: 28).

$\mathrm{Na}$ osnovu svih ranije iznetih primera izvodimo zaključak da odstupanje od stilski neutralnog oblika direktnih parcijalnih pitanja, u kojima imenička upitnoodnosna zamenica nije upotrebljena u inicijalnoj, već u finalnoj poziciji, ne zavisi od jezičkog raslojavanja, već od konkretne funkcije i upotrebe koju upitna reč ima $\mathrm{u}$ datom kontekstu. Raspored ostalih rečeničnih konstituenata je uslovno govoreći slobodan usled očuvanog flektivnog sistema u vidu deklinacije po padežima.

\section{KONTRASTIVNA ANALIZA DIREKTNIH PARCIJALNIH PITANJA IZVEDENIH POMOĆU PROSTIH UPITNIH ZAMENICA U FRANCUSKOM JEZIKU I NJIHOVIH EKVIVALENATA U SRPSKOM JEZIKU}

\subsection{Korpus}

$\mathrm{U}$ ovom delu rada, kontrastivna jezička analiza prostih upitnih zamenica $\mathrm{u}$ direktnim parcijalnim pitanjima na francuskom jeziku i njihovih ekvivalenata na

$14 \quad$ Lj. Popović navodi sledeće primere: Mali i tihi Sesil [...] uhvatio je [...] nit koja će posle smrti Elizabete [...] vezati dva bratska naroda i dovesti na presto Engleske, koga? škotskog kralja (Isidora Sekulić, Mir i nemir (ogledni radovi), 1957) (Popović, 2004: 253). 
srpskom jeziku biće zasnovana na analizi dela korpusa sastavljenog od odabranih izvornih dramskih književnih dela na francuskom i srpskom, kao i njihovih objavljenih prevoda na jedan od ta dva jezika. Na francuskom jeziku, korpusom su obuhvaćena direktna parcijalna pitanja ekscerpirana iz tri dramska dela: Alber Kami, Kaligula (Albert Camus, Caligula) iz 1938. g. ${ }^{15}$ (ACC), A. Kami, Nesporazum (A. Camus, Le malentendu) iz 1944. g. (ACM) i Margerit Diras, Hirošimo, ljubavi moja (Marguerite Duras, Hiroshima, mon amour) iz 1960. g. (MDH). Na srpskom jeziku, korpusom su obuhvaćena direktna parcijalna pitanja ekscerpirana iz tri dramska dela: Jovan Sterija Popović, Rodoljupci objavljeno posthumno, napisano približno 1854. g. (JSPR), Ljubomir Simović, Putujuće pozorište Šopalović iz 1986. g. (LJSŠ) i Dušan Kovačević, Profesionalac iz 1989. g. (DKP). U skraćenicama koje označavaju književne izvore, malo slovo a upućuje na originalno delo na francuskom ili srpskom (ACCa, ACMa, MDHa, JSPRa, LJSŠa, $\mathrm{DKPa}$ ), a malo slovo $\mathrm{b}$ na objavljen prevod na jednom od ta dva jezika (ACCb, $\mathrm{ACMb}, \mathrm{MDHb}$, JSPRb, LJSŠb, DKPb).

\subsection{Parcijalna pitanja sa prostim upitnim zamenicama u francuskom $i$ imeničkim upitno-odnosnim zamenicama u srpskom jeziku}

U našem korpusu, prostoj upitnoj zamenici za lica u francuskom jeziku qui u funkciji subjekta (49b) i imenskog dela predikata (50a) odgovara u srpskom imenička upitno-odnosna zamenica $k o$ u nominativu (49a, 50b):

\begin{tabular}{|c|c|c|}
\hline $\begin{array}{l}\text { (Graja i vika rastu. } \\
\text { Uleće Milun.) }\end{array}$ & $(49 b)$ & $\begin{array}{l}\text { (Le vacarme et les cris } \\
\text { augmentent }\end{array}$ \\
\hline Milun: Ko pravi ovde & & Miloun surgit.) \\
\hline nered? & & Miloun : Qui fait du tapage, \\
\hline Treća građanka: Pitaj & & $\underline{i c i} ?$ \\
\hline njih! & & $\begin{array}{l}3^{e} \text { femme : T'as qu'à } \\
\text { demander à ceux-là ! }\end{array}$ \\
\hline Druga građanka: & & $2^{e}$ femme : Des espèces de \\
\hline $\begin{array}{l}\text { Barabe belosvetske! } \\
\text { (LJSŠa: } 10)\end{array}$ & & $\begin{array}{l}\text { débauchés, des vagabonds! } \\
\text { (LJSŠb: } 15-16 \text { ) }\end{array}$ \\
\hline
\end{tabular}

\footnotetext{
Navodimo godinu prvog izdanja, a bibliografski podaci o izdanju kojim smo se mi služili u svrhu našeg istraživanja nalaze se u spisku literature. Ukoliko je delo prvi put objavljeno posthumno, navodimo podatak o tome za koji period se vezuje nastanak datog književnog dela.
} 
(50a) Maria : Je viens

rejoindre mon mari.

(Elle entre.)

Martha (la regardant) :

Qui est votre mari?

Maria : Il est arrivé

ici hier et devait me

rejoindre ce matin. Je

suis étonnée qu'il ne l'ait

pas fait. (ACMa: 238) (50b)

Marija: Došla sam po svog muža.

(Ulazi.)

Marta (gledajući je): $\underline{\text { Ko je }}$ vaš muž?

Marija: Doputovao je juče, $i$ jutros je trebalo da dođe po mene. Čudi me što to nije učinio.

(ACMb: 134)

U francuskom jeziku, u funkciji subjekta, prosta upitna zamenica qui može se javiti i u svom proširenom obliku: qui est-ce qui, te bi primer (49b) iz našeg korpusa mogao da glasi i: Qui est-ce qui fait du tapage, ici ? U srpskom jeziku, prevod bi ostao isti, odnosno zamenica $k o$, u funkciji subjekta, ostala bi u nominativu ${ }^{16}$.

Prostoj upitnoj zamenici za lica $\mathrm{u}$ francuskom jeziku qui $\mathrm{u}$ funkciji direktnog objekta (51b) odgovara u srpskom imenička upitno-odnosna zamenica ko u akuzativu (51a):

$$
\begin{aligned}
& \text { Čovek: [...] I čovek ti je } \\
& \text { poverovao, zagrlio te, } \\
& \text { potap̌́ao po ramenu- } \\
& \text { bilo mu je drago } \\
& \text { što se nisi odrodio, } \\
& \text { i upitao te: Koga najčešće } \\
& \text { viđašs? Pa... i tu si, kao sad, } \\
& \text { stao i pokušao da se setiš } \\
& \text { bar jednog imena. }
\end{aligned}
$$$$
\text { (DKPa: 133) }
$$

L'homme : [...] Et l'homme
t'a cru, il t'a pressé dans
ses bras, t'a donné quelques
tapes sur l'épaule, content
que tu ne te sois pas renié,
et il t'a demandé : «Et qui
vois-tu le plus souvent? ».
Là aussi, comme maintenant,
tu étais debout, et essayais
de te souvenir d'au moins un
nom. (DKPb: 18-19)

$\mathrm{U}$ francuskom jeziku, u navedenoj funkciji, prosta upitna zamenica qui može se javiti i u svom proširenom obliku: qui est-ce que, te bi primer (51b) iz našeg

\footnotetext{
Vjekoslav Ćosić sugeriše da bi se, u izvesnom smislu, mogli smatrati približno ekvivalentnim oblicima: Tko li je došao? i « Qui est-ce qui est venu ?» (Ćosić, 2006: 57). Međutim, rečca li u parcijalnim pitanjima uglavnom upućuje na retorska pitanja, dok u francuskom jeziku prošireni oblik pitanja (upitna reč + est-ce que / est-ce qui) ne mora da nosi takvo značenje, već se takvim oblikom upravo može dodatno insistirati na upitnom značenju. Osim toga, potrebno je posebno napomenuti da postoji i slučaj kada prošireni oblik pitanja nema alternativni prosti oblik, kao što je to slučaj kod proste upitne zamenice za stvari i pojmove u funkciji subjekta: qu'est-ce qui.
} 
korpusa mogao da glasi i: Qui est-ce que tu vois le plus souvent?, pri čemu bi prevod na srpski ostao isti.

U francuskom jeziku, padeška značenja iskazuju se pomoću predloga, te je takav slučaj i narednim primerima gde je značenje dativa upitno-odnosne zamenice $k o(52 \mathrm{~b}, 53 \mathrm{a})$ iskazano kombinacijom predloga vers + prosta upitna zamenica qui (52a), odnosno kombinacijom predloga $a ̀+$ prosta upitna zamenica qui (53b):

Martha $[\ldots]:[\ldots]$ Vers qui donc, dans le monde, aurais-je pu me tourner, sinon vers celle qui avait tué en même temps que moi ? Mais je me trompais. Le crime aussi est une solitude, même si on se met à mille pour l'accomplir. (ACMa: 245)

(53a) Ja: [...] A šta mislite, kako sam mogao da pročitam knjigu koja vam je vraćena pre pet meseci?

Nije vam vraćena?

A kome ste je predali? $\mathrm{Pa}$, izvolite, tražite je od njega...

(DKPa: 130) (52b) Marta [...]: [...] Kome sam ja, u ovom svetu, mogla da se okrenem, ako ne onoj koja je ubijala zajedno sa mnom? Međutim, prevarila sam se. I zločin je usamljenost, čak i ako se hiljadu ljudi udruži da ga izvrši. (ACMb: 137)

(53b) Moi : [...] À votre avis, comment aurais-je pu lire un livre qui vous a été renvoyé il y a cinq mois?...

On ne vous l'a pas renvoyé

? Et à qui l'avez-vous remis

$?$ Alors, je vous en prie, demadez-le lui... (DKPb: 9)

U francuskom jeziku, u prethodnim primerima, mogli su da budu upotrebljeni i prošireni upitni oblici, te da glase: Vers qui donc, dans le monde, est-ce que j'aurais pu me tourner, sinon vers celle qui avait tué en même temps que moi? (52a), Et à qui est-ce que vous l'avez remis? (53b), pri čemu bi prevod na srpski ostao isti.

U našem korpusu, prostoj upitnoj zamenici za stvari i pojmove $\mathrm{u}$ francuskom jeziku que (qu') odgovara u srpskom jeziku imenička upitno-odnosna zamenica: $\check{s} t a$. U francuskom jeziku, ova zamenica, u funkciji subjekta, može se javiti jedino u svom proširenom vidu qu'est-ce qui: 
(54a) Caesonia (même jeu) :

Et pourquoi vous battiezvous?

Cherea: Nous nous battions pour rien.

Coesonia : Alors, ce n'est pas vrai.

Cherea : Qu'est-ce qui n'est pas vrai?

Coesonia : Vous ne vous battiez pas. (ACCa: 54-55)

(55a) Ja: Zašto mi ostavljate ključeve?

Marta: Neću više dolaziti. [...]

Ja: Zašto?

Šta se desilo? Šta je bilo, Marta?

(Gledala me je ćuteći. Oči su joj bile mutne i uplašene.)

(DKPa: 161) (54b) Cezonija (istim tonom): A zbog čega ste se tukli? Hereja: Ni zbog čega.

Cezonija: Ma hajde, to nije istina.

Hereja: Šta nije istina?

Cezonija: Niste se tukli. (ACCb: 54)

(55b) Moi : Pourquoi me laissezvous les clés?

Marta: Je ne viendrai plus. [...]

Moi : Mais pourquoi?

Qu'est-ce qui s'est passé $?$ Qu'est-il arrivé, Marta

? (Elle me regardait en silence, les yeux embués et apeurés.) (DKPb: 96-97)

U primeru (55b) naveden je i jedini slučaj kada, u francuskom jeziku, upitna zamenica que (qu') može imati funkciju subjekta, a to je kada uz unipersonalne glagole vrši funkciju ,pravog subjekta“: Qu'est-il arrivé, Marta? U srpskom jeziku, imenička upitno-odnosna zamenica za stvari i pojmove šta uvek ima isti oblik (nominativ) kada je upotrebljena u funkciji subjekta.

U našem korpusu, prostoj upitnoj zamenici za stvari i pojmove u francuskom jeziku que (qu') u funkciji direktnog objekta, bez obzira na to da li je upotrebljena u svom neproširenom $(56 \mathrm{a}, 58 \mathrm{~b})$ ili proširenom vidu $(57 \mathrm{a}, 58 \mathrm{~b})$, odgovara u srpskom imenička upitno-odnosna zamenica šta u akuzativu (56b, 57b, 58a): 
(56a) Caligula : C'était difficile à trouver.

Hélicon : Quoi donc?

Caligula: Ce que je voulais.

Hélicon: Et que voulais-tu

$?$

Caligula (toujours naturel)

: La lune.

(ACCa: 24)

(57a) Caligula (brutalement) :

Qu'est-ce que vous voulez?

L'intendant : Nous étions inquiets, César. (ACCa: 31)

(58a) Šerbulić: [...] Rodoljupci, vi rodoljupci!

Šta ste za narod učinili?

Smrdić: A šta ste učinili vi?

Šerbulič: Više od vas.

(JSPRa: 205) (56b) Kaligula: Bilo je teško naći.

Helikon: A šta to?

Kaligula: Ono što sam želeo.

Helikon: A šta si želeo?

Kaligula (i dalje prirodno):

Mesec.

(ACCb: 41) (57b) Kaligula (grubo):

Šta hoćete?

Upravitelj palate: Brinuli smo se, Cezare. (ACCb: 44)

(58b) Šerbulić : [...] Des patriotes, vous, des patriotes!

Qu'avez-vous fait pour la nation?

Smrdić : Et vous, qu'est-ce que vous avez fait?

Šerbulić : Plus que vous. (JSPRb: 112)

U primeru (56a), prosta upitna zamenica za stvari i pojmove upotrebljena je i samostalno, kada ona nužno mora da ima naglašeni oblik quoi, dok se u srpskom jeziku uvek koristi isti oblik upitno-odnosne zamenice $\check{s} t a$.

$\mathrm{U}$ francuskom jeziku, nužno se koristi i naglašeni oblik quoi kada se nađe $\mathrm{u}$ finalnoj poziciji direktnih parcijalnih pitanja (specifičnoj za familijarni jezik), dok je u srpskom jeziku inicijalna pozicija upitnih reči u direktnim parcijalnim pitanjima stilski neutralna: 
(59a) Blagoje: O čemu ovaj bunca? [...]

Simka: [...] Neka vam objasne glumci, ja ne umem!

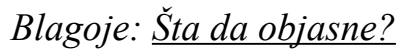

(Gini)

I zašto je kazo da se odričeš

sina?

Gina: Zato što je momentalni bolesnik!

Blagoje: Šta kažeš da je?

Gina: Mene naziva majkom, a tebe ocem! Kad pogledam njega ludog, i tebe pijanog, ne bi me čudilo $i$ da je istina!

(LJSŠa: 49-50) (59b) Blagoyé : Mais il déraille, celui-là ! [...]

Simca : [...] Les acteurs n'ont qu'à vous expliquer, moi j'en suis incapable. Blagoyé : Expliquer quoi ? (à Gina) Et pourquoi il a dit que tu renies à ton fils? Gina : Parce qu'il est " momentalement» malade!

Blagoyé : Tu dis qu'il est quoi? Gina : Moi, il m'appelle mère, toi père! À vous voir tous les deux, lui complètement fou et toi saôul, ben j'serais pas surprise que ce soit vrai. (LJSŠb: 77-79)

Kao što smo to već imali prilike da vidimo, u francuskom jeziku, značenja zavisnih padeža iskazuju se pomoću predloga, te je takav slučaj i u narednim primerima gde je upotrebljena kombinacija predloga de + prosta upitna zamenica quoi (60a, 61b), kao i kombinacija predloga en + prosta upitna zamenica quoi (62b), čemu, u srpskom jeziku, odgovara upitno-odnosna zamenica šta u odgovarajućem padežu: lokativu (60b), genitivu (61a), akuzativu (62a):

(60a) Cherea (calme et s'asseyant) De quoi s'agit-il?

Premier patricien et le vieux patricien (ensemble) : La conjuration est découverte. (ACCa: 122)

Hereja (smireno, sedajući):

U čemu je stvar?

Prvi patricije i stari patricije (zajedno): Zavera je otkrivena. (ACCb: 82) 
(61a) Sofija: Što ste me prepali!

Drobac: Plivaš i po noći?

Sofija: Ko ste vi?

Drobac: Nije te stra?

Sofija: Čega da me bude strah?

Drobac: Ko zna ko more iz ovog mraka da naiđe.

(LJSŠa: 62-63)

(62a) Lepršić: [...] U Evropi ima osamdeset miliona Slavjana, i Evropa mora biti slavjanska! Žutilov: Šta se to nas tiče?

Lepršić: : Šta se tiče?

To je greh protiv narodnosti; a greh protiv narodnosti veći je u sadašnje vreme nego smrtni greh.

(JSPRa: 171) (61b) Sophie: Comme vous $m$ 'avez fait peur!

Le Broyeur: Tu t'baignes aussi la nuit?

Sophie : Qui êtes-vous?

Le Broyeur : T'as pas peur

?

Sophie: De quoi aurais-je peur?

Le Broyeur : N'importe qui peut

s'amener dans le noir.

(62b) Leprsicic: 101) [...] Il y a en

Europe

quatre-vingts millions de

Slaves,

aussi l'Europe doit être

slave!

Žutilov : En quoi cela nous concerne-t-il?

Lepršić : En quoi ça nous concerne? C'est un péché contre la nation; et un péché contre la nation est plus grave à l'heure actuelle qu'un péché mortel. (JSPRb: 62-63)

U francuskom jeziku, u prethodnim primerima, mogli su da budu upotrebljeni i prošireni upitni oblici, te da glase: De quoi est-ce qu'il s'agit ? (60a), De quoi est-ce que j'aurais peur? (61b), En quoi est-ce que cela nous concerne? (62b), pri čemu bi prevod na srpski ostao isti.

$\mathrm{Na}$ kraju ovog poglavlja dajemo tabelarni prikaz prostih upitnih zamenica $\mathrm{u}$ francuskom jeziku i njihovih ekvivalenata u srpskom jeziku: 


\begin{tabular}{|c|c|c|}
\hline \multicolumn{3}{|c|}{$\begin{array}{l}\text { Tabela 4: Proste upitne zamenice za lica u francuskom jeziku } \\
\text { i njihovi ekvivalenti u srpskom jeziku }\end{array}$} \\
\hline \multicolumn{2}{|c|}{ FRANCUSKI JEZIK } & \multirow[t]{2}{*}{ SRPSKI JEZIK } \\
\hline FUNKCIJA & OBLIK & \\
\hline \multirow[t]{2}{*}{ subjekat } & $q u i$ & \multirow{8}{*}{$\begin{array}{l}\text { imenička upitno-odnosna } \\
\text { zamenica za lica } K O \\
\text { u odgovarajućem padežu }\end{array}$} \\
\hline & qui est-ce qui & \\
\hline \multirow[t]{2}{*}{ imenski deo predikata } & $q u i$ & \\
\hline & (qui est-ce que) & \\
\hline \multirow[t]{2}{*}{ direktni objekat } & $q u i$ & \\
\hline & qui est-ce que & \\
\hline \multirow{2}{*}{$\begin{array}{l}\text { predlog }+ \text { prosta } \\
\text { upitna zamenica }\end{array}$} & predlog $+q u i$ & \\
\hline & (predlog + qui est-ce que) & \\
\hline
\end{tabular}

\begin{tabular}{|l|c|c|}
\hline \multicolumn{2}{|c|}{$\begin{array}{c}\text { Tabela 5: Proste upitne zamenice za stvari i pojmove u francuskom jeziku } \\
\text { i njihovi ekvivalenti u srpskom jeziku }\end{array}$} \\
\hline \multicolumn{2}{|c|}{ FRANCUSKI JEZIK } & \multirow{2}{*}{ SRPSKI JEZIK } \\
\hline FUNKCIJA & OBLIK & \multirow{2}{*}{$\begin{array}{c}\text { imenička upitno- } \\
\text { odnosna zamenica za } \\
\text { stvari i pojmove ŠTA u } \\
\text { odgovarajućem padežu }\end{array}$} \\
\cline { 2 - 2 } subjekat & qu'est-ce qui & \\
\hline imenski deo predikata & que & \\
\cline { 2 - 2 } & qu'est-ce que & \\
\hline direktni objekat & que / quoi & \\
\cline { 2 - 2 } & qu'est-ce que & \\
\hline predlog + prosta & predlog + quoi & \\
upitna zamenica & (predlog + quoi est-ce que) & \\
\hline
\end{tabular}

\section{ZAKLJUČAK}

Direktna parcijalna pitanja izvedena pomoću prostih upitnih zamenica u francuskom jeziku pokazuju visok stepen varijabilnosti kako na strukturnom tako i na stilskom planu. Iako proste upitne zamenice $u$ francuskom jeziku spadaju $u$ nepromenljivu vrstu reči, njihova strukturna varijabilnost ogleda se u činjenici što, pored toga što se njihov oblik razlikuje u zavisnosti od toga da li se odnose na bića (qui) ili na stvari i pojmove (gde se razlikuje nenaglašeni oblik: que/qu' i naglašeni oblik: quoi), on se razlikuje i u zavisnosti od toga koju funkciju upitna 
zamenica ima u konkretnom upitnom iskazu. Izuzev oblika qu'est-ce qui za lica i pojmove u funkciji subjekta, ostale proste upitne zamenice često imaju dvojne, alternativne upitne oblike za pojedine funkcije: neproširene (koji zahtevaju upotrebu inverzije osim ako upitna reč ima funkciju subjekta) i proširene pomoću upitnog izraza est-ce que, est-ce qui (koji zahtevaju isti red reči kao u izjavnoj rečenici). Dok neprošireni upitni oblici mahom zahtevaju upotrebu inverzije u direktnim parcijalnim pitanjima (izuzev u slučaju kada upitna reč vrši funkciju subjekta), upotreba paralelnih proširenih upitnih oblika omogućava zadržavanje kanonskog reda reči specifičnog za izjavne rečenice. Uprkos normativnim načelima koji propisuju upotrebu inverzije uz neproširene upitne oblike prostih upitnih zamenica, u razgovornom jeziku često dolazi do odstupanja od ovih pravila, i to tako da se upitna zamenica koristi u finalnoj poziciji ili, čak, u inicijalnoj poziciji prilikom čega dolazi do direktnog kršenja propisanog gramatičkog pravila. Prema tome, usled brojnih elementa koji su podložni varijaciji, direktna parcijalna pitanja izvedena pomoću prostih upitnih zamenica podrazumevaju izrazito složen sistem u francuskom jeziku.

U gramatikama francuskog jezika namenjenim srbofonim govornicima, proste upitne zamenice u francuskom jeziku izjednačavaju se sa imeničkim upitnoodnosnim zamenicama u srpskom jeziku. Oslanjajući se na relevantnu normativnu i deskriptivnu literaturu, kao i na rezultate naše kontrastivne analize korpusa sastavljenog od književnih dramskih dela na francuskom i srpskom jeziku, možemo da ustanovimo da je reč o semantički ekvivalentnim oblicima različitih strukturnih i stilskih karakteristika. Za razliku od francuskog jezika, u srpskom jeziku imeničke upitno-odnosne zamenice za lica ko i za stvari i pojmove šta spadaju u promenljivu vrstu reči (deklinacija po padežima podrazumeva sve padeže izuzev vokativa). U srpskom jeziku, u direktnim parcijalnim pitanjima, upitne reči uopšteno, pa tako i imeničke upitno-odnosne zamenice, zauzimaju inicijalnu poziciju u direktnim pitanjima. Ovaj položaj smatra se stilski neutralnim, a iznimna odstupanja od tog redosleda objašnjavaju se funkcijom koju upitne zamenice imaju u konkretnom upitnom iskazu, a ne faktorima jezičkog raslojavanja. Budući da je u srpskom jeziku očuvan flektivni sistem u vidu deklinacije, red reči je generalno slobodniji nego u francuskom jeziku gde je red reči vezani (fiksni). Iako je u srpskom jeziku u direktnim parcijalnim pitanjima česta upotreba inverzije iza imeničke upitno-odnosne zamenice kada ona ne vrši funkciju subjekta, ovaj redosled nije strogo određen. Prema tome, u srpskom jeziku, odstupanje od inverzije nema istu stilsku vrednost kao u francuskom jeziku, kao što ni, uopšteno govoreći, jezička varijacija koja odatle proizilazi nema istu ulogu u oba ova jezika. 
Nataša Radusin-Bardić

\title{
DIRECT WH-QUESTIONS INTRODUCED BY SIMPLE INTERROGATIVE PRONOUNS IN FRENCH AND ITS EQUIVALENTS IN SERBIAN
}

\author{
SUMMARY
}

The WH-questions refer to a question type using the interrogative words to specify the information that is desired. The direct WH-questions introduced by simple interrogative pronouns in French show a wide range of variability. The simple interrogative pronouns relate to the nature and the identity of the referent. Their form varies depending upon the origin itself of the referent: in principle, qui is used for human animates only, que/qu' is used for inanimates and generally non-human subjects. The simple interrogative pronouns for inanimates and generally non-human subjects have the unstressed (que/qu') and the stressed form (quoi). The proper usage of the unstressed or the stressed form of the simple interrogative pronoun depends upon its position in the sentence, its dependent or independent usage and the fact that it is accompanied or not by a preposition. Beside the origine of the referent, the form of the simple interrogative pronouns varies depending upon the function of the interrogative pronoun in the sentence (subject, subject complement, direct object complement, prepositional complement). Except for a non-human subject (qu'est-ce qui), the simple interrogative pronouns have its short or long forms depending upon the function in the sentence (the long form is enlarged with est-ce qui for subjects and est-ce $q u e$ for objects). The main advantage of the long form is that it does not require inverting the order of the subject and the verb as it needs to be usually done with the short forms (except for the subjects). However, in the informal, conversational language, the inversion tends to be avoided despite the normative rules. Finally, as a result of these tendencies in the modern French language, the direct WH-questions introduced by simple interrogative pronouns show a wide range of a stylistic and structural variability.

The aim of our work was to determine the equivalent forms in Serbian of the direct WHquestions introduced by simple interrogative pronouns in French. In Serbian, the interrogative pronouns for human animates $k o$ and for generally non-human subjects šta have six different case forms. They usually occupy the initial position in the sentence which has the neutral stylistic value. The analyse of the direct WH-questions introduced by simple interrogative pronouns in French and Serbian is based on the normative and descriptive literature, as well as on the analyse of the selected theatrical works in French and Serbian and its published translations in both of these languages.

Keywords: WH-questions, interrogative pronouns, French, Serbian. 


\section{LITERATURA}

Barić, E., Lončarić, M., Malić, D., Pavešić, S., Peti, M., Zečević, V. \& Znika, M. (1997). Hrvatska gramatika (2. izd.). Zagreb: Školska knjiga.

Brabec, I., Hraste, M. \& Živković, S. (1968). Gramatika hrvatskosrpskoga jezika (8. izd.). Zagreb: Školska knjiga.

Chevalier, J.-C., Arrivé, M., Blanche-Benveniste, C. \& Peytard, J. (1964). Grammaire Larousse du français contemporain. Paris: Larousse.

Ćosić, V. (2006). Modalité interrogative en croate et en français : à propos du mot $l i$. U: Soutet, O. (ured.) (2006). Études de linguistique contrastive (str. 47-65). Paris: PUPS (Presses de l'Université Paris-Sorbonne).

Delatour, Y., Jennepin, D., Léon-Dufour, \& Teyssier, B. (2004). Nouvelle Grammaire du Français. Cours de Civilisation Française de la Sorbonne. Paris: Hachette F.L.E.

Drašković, V. (1992). Gramatika francuskog jezika za osnovnu školu (9. izd.). Beograd: Zavod za udžbenike i nastavna sredstva, Novi Sad: Zavod za izdavanje udžbenika.

Grevisse, M. (1969). Le bon usage. Grammaire française avec des remarques sur la langue française d'aujourd'hui (9. izd.). Gembloux: Éditions J. Duculot, S. A.

Klajn, I. (2006). Gramatika srpskog jezika za strance. Beograd: Zavod za udžbenike.

Le Goffic, P. (1993). Grammaire de la Phrase Française. Paris: Hachette Supérieur, Hachette Université Langue française, Hachette.

Mirić, D. (1994). Upitni iskaz u ruskom i srpskom jeziku (doktorska disertacija, rukopis). Novi Sad: Filozofski fakultet.

Papić, M. (1992). Gramatika francuskog jezika: strukturalna morfosintaksa (3. izd.). Beograd: Zavod za udžbenike i nastavna sredstva, Novi Sad: Zavod za izdavanje udžbenika.

Piper, P., Antonić, I., Ružić, V., Tanasić, S., Popović, Lj. \& Tošović, B. (2005). Sintaksa savremenog srpskog jezika: prosta rečenica. Beograd: Institut za srpski jezik SANU, Beogradska knjiga, Novi Sad: Matica srpska.

Popović, Lj. (2004). Red reči u rečenici (2. izd.). Beograd: Društvo za srpski jezik i književnost Srbije.

Riegel, M., Pellat, J.-C. \& Rioul, R. (2004). Grammaire méthodique du français (3. izd.). Paris: PUF.

Stanojčić, Ž. \& Popović, Lj. (2010). Gramatika srpskoga jezika: za gimnazije i srednje škole (12. izd.). Beograd: Zavod za udženike.

Stevanović, M. (1989). Savremeni srpskohrvatski jezik (gramatički sistemi i književnojezička norma). II Sintaksa (4. izd.). Beograd: Naučna knjiga.

\section{REČNICI}

Jovanović, S. A., Čemerikić, J., Damnjanović, D., Đorđević, M. \& Jovanović, K. (1991). Savremeni francusko-srpskohrvatski rečnik sa gramatikom, I. Beograd: Prosveta.

LPR Le Petit Robert, CD-ROM, version 2.1, 2001.

TLFI Le Trésor de la langue française informatisé (2013). ATILF (Analyse et traitement informatique de la langue française), CNRS (Centre national de la recherche scientifique), Nancy Université. Preuzeto sa http://www.cnrtl.fr/definition/ 


\section{KORPUS}

Skraćenice za književna dela iz korpusa:

ACCa Camus, A. (1972). Caligula. U: « Caligula » suivi de « Le malentendu ». Nouvelles versions (str. 9-151). Paris: Gallimard.

ACCb Kami, A. (2008). Kaligula. U: Pozorište (str. 33-95). Beograd: Paideia (prevela A. Moralić).

ACMa Camus, A. (1972). Le malentendu. U: "Caligula » suivi de "Le malentendu ». Nouvelles versions (str. 153-249). Paris: Gallimard.

ACMb Kami, A. (2008). Nesporazum. U: Pozorište (str. 97-139). Beograd: Paideia (prevela A. Moralić).

DKPa Kovačević, D. (1994). Profesionalac. U: Odabrane drame, II (str. 127-162). Beograd: Vreme knjige.

DKPb Kovačević, D. (2000). Le Professionnel. Lausanne: L’Âge d’Homme (preveli A. Renoue i V. Čejović).

JSPRa Sterija Popović, J. (1990). Rodoljupci. U: Roman bez romana (str. 161-226). Sarajevo: Oslobođenje.

JSPRb Sterija Popović, J. (2004). Les Patriotes. Vršac: Književna opština Vršac (preveo P.-L. Thomas).

LJSŠa Simović, Lj. (1986). Putujuće pozorište Šopalović. Novi Sad: Sterijino pozorje.

LJSŠb Simovitch, L. (1989). Le théâtre ambulant Chopalovitch. Lausanne: L'Âge d'Homme (preveli B. Legras i A. Renoue).

MDHa Duras, M. (1960). Hiroshima, mon amour. Scénario et dialogue. Paris: Gallimard.

MDHb Diras, M. (1994). Hirošimo, ljubavi moja. Beograd: Prosveta (prevela N. Bojić).

Skraćenice za filmove iz korpusa:

ELM Le fabuleux destin d'Amélie Poulain (Jean-Pierrre Jeunet, 2001).

FDAP Entre les murs (Laurent Cantet, 2008). 